\title{
RAINFALL AND AGRICULTURAL PRODUCTION IN BOTSWANA
}

\author{
Paul VOSSEN \\ Via Milano, 14 \\ 21027 Ispra (VA) \\ Italy
}

PRESENT FIELD OF INTEREST: crop state monitoring and yield forecasting for the C.E.C.

\section{SUMMARY}

The interannual variability of traditional, rainfed agricultural production of Botswana, a country with a typical semi-arid climate, is almost completely accounted for by the quality of the rainy season. It appears that the variability of the national cattle death ratio, total planted area and crop yield are, for more than $95 \%$ accounted for by rainy season conditions. As a result, also the nutritional state of the population highly correlates with rainfall.

Despite the severe droughts of 1978/79 and 1985/86, farmers were not discouraged to practice agriculture: in fact, crop production shows a significant positive time trend which becomes apparent, when the trend and the rainy season conditions are analysed in combination with each other.

As part of this study, models were developed and validated for a precise and areawise agricultural rainy season quality monitoring and for national agricultural production forecasting in Botswana. One of these models could possibly also be used for the areawise assessment of risks for malnutrition of children under five years old. 


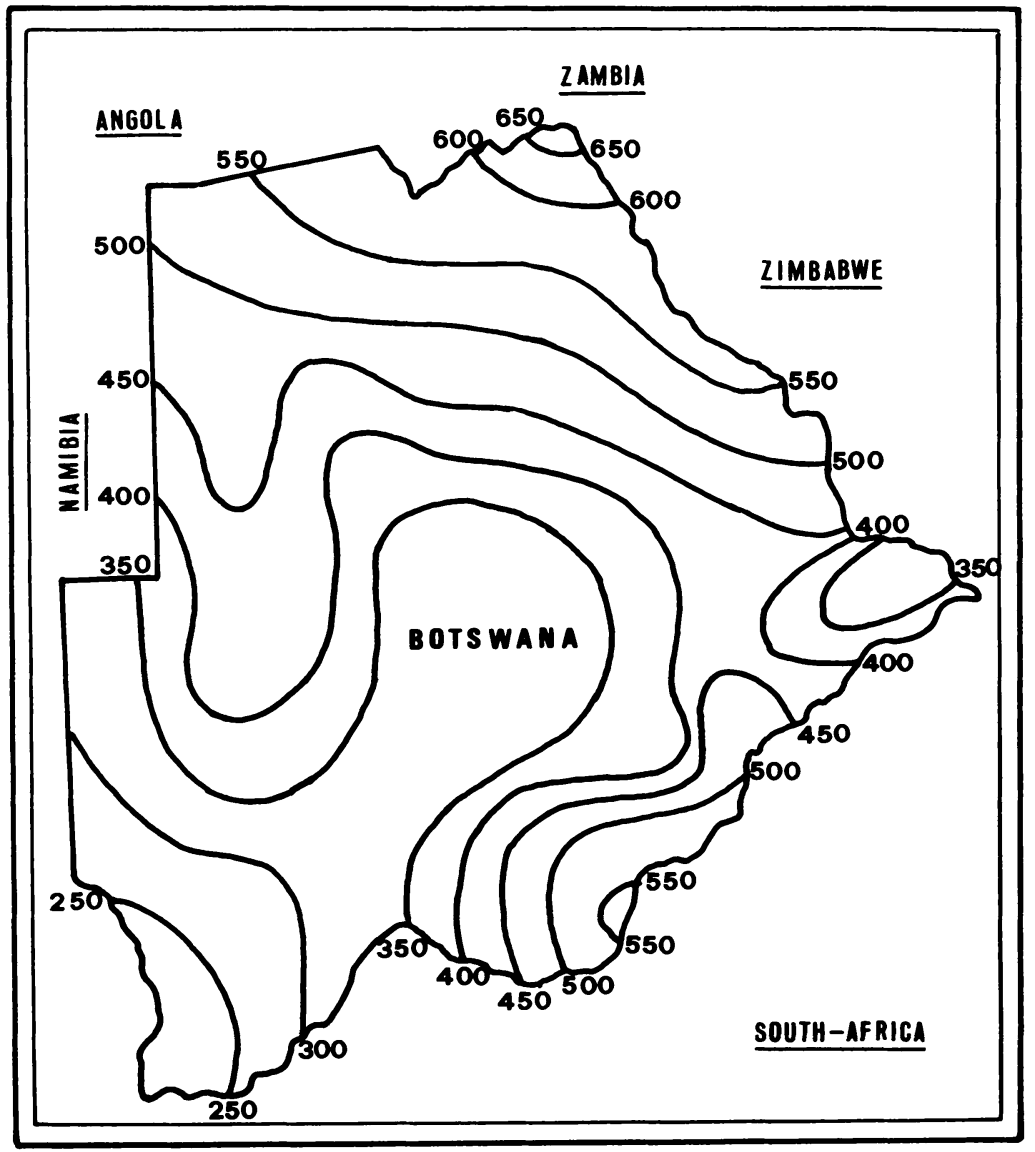

Figure 1: Mean annual rainfall of Botswana, in $\mathrm{mm}$. (After Bhalotra, 1985) 
KEY WORDS: agricultural planning, Botswana, crop state monitoring, crop yield forecasting, human nutrition, rainfall, semi-arid, time trend.

\section{INTRODUCTION}

Botswana $\left(18^{\circ}-27^{\circ} \mathrm{S} ; 5^{\circ}-29^{\circ} \mathrm{E}\right.$; approximately $\left.582000 \mathrm{~km}^{2}\right)$ has a typical semi-arid climate, which is, at least for non-climatologists, quite comparable with the climate of the Sahel. The most striking characteristic of this semi-aridity is not a lack of rainfall as such, but the complete unpredictability of its precise distribution within a rainy season and the high ratio between the water requirements of the vegetation (dictated by the subtropical conditions) and the rainfall amounts. For example, the rainy season can start at any date between mid-October and mid-December and end between mid-February and mid-May. Within the rainy season, dry spells of more than a month, resulting in severe yield reduction (1) are common and the total length of all dry spells put together exceeds in most years the total length of the period that crop growth without water stress would have been possible.

In terms of satisfying the water requirements of agricultural crops, it might be mentioned that P.E.T. ${ }^{(*)}$ exceeds annual rainfall by a factor of 3-4 in the extreme north-east (the Chobe Game Reserve) and 8-10 in the extreme south-west of the country (the Kalahari desert). Figure 1 (after Bhalotra, 1985) shows Botswana's mean annual rainfall.

The agro-climate of Botswana can thus not be considered as particularly favourable for rainfed crop cultivation and the exploitation of the natural vegetation by locally adapted livestock is therefore the most important agricultural activity. This is reflected in the fact that the national cattle herd size is more than twice the population (1.1 million people). Natural vegetation is indeed more adapted to the local climate and local cattle breeds are relatively mobile and can, depending upon the spatial rainfall distribution, be moved to more productive grazing areas or drinking water supply sites.

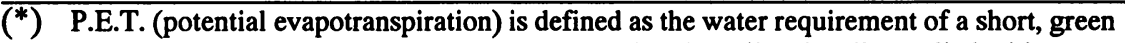
grass cover, actively growing, completely covering the soil and well-supplied with nutrients and water. P.E.T. can also be calculated with formulas that use meteorological information as only input data. In commercial agriculture, P.E.T. is used for the design and daily operation of irrigation schemes. 
Crop cultivation is nevertheless not negligible, at least in terms of human activity, as more than $80 \%$ of the population has still some income and/or food supply from crops. Some food crops are even actively cultivated in parts of the Kalahari desert with less then $300 \mathrm{~mm}$ of rain. (However, in these areas, the commercialisation of the wild growing medical grapple plant (against reumatism) is economically more important (3)).

In terms of production and contribution to the gross national product, crop cultivation is much less important: the total national 1977 - 1986 average planted area was approximately 220000 ha. (This area is almost identical to the total acreage of tobacco in the E.E.C.). The 1978/79 - 1985/86 average crop yield was only about $150 \mathrm{~kg}$ per planted hectare. In fact, where Botswana exports beef and livestock products, it has to import, on average, more than half of its national requirements of cereals and pulses.

\section{FIELD SURVEYS AND AGROMETEOROLOGICAL MONITORING}

Quantitative information on the agricultural production is made available through a dense network of agricultural enumerators, who obtain their information from field observations, visits to farms, interviews, etc. Although providing correct information, agricultural statistics based on field surveys have the disadvantage of a limited usefulness because the final figures only become available some time after the end of the season. Agrometeorological rainy season quality monitoring on the contrary uses meteorological data which can be made available by radio or telephone within a day or so after its observation. Such methods are based on quantified relations between agricultural production factors and growing season conditions and are in operational use in the U.S.A., in the U.S.S.R., in Australia and in several European countries.

The precision of the information provided by these methods will always need a posteriori confirmation when the results of the field surveys become available , but they have nevertheless the enormous advantage of providing qualitative areawise information on crop state and expected yields, during the rainy season. Also in Africa, the availability of such quantified relations would greatly facilitate a more precise agricultural planning and decision making and, depending upon the spatial representativity of the meteorological network, a timely, areawise monitoring of the quality of a current rainy season. But contrary to what one would expect, such methodologies were not available in Africa until very recently. It seems that agricultural research has been emphasising too much on increasing the production and on selecting or adapting crop varieties or cattle breeds to local conditions, and not 
enough (or not at all) on quantifying the variability of agricultural production in relation to climatic variability.

This is not only the case for Botswana, but for all the semi-arid areas in Africa. Strange enough, and although it has been known for centuries that lack of rainfall is a major hazard to the agriculture of more than half of Africa, the introduction of most operational applications of agricultural meteorology on national agricultural planning in Africa, goes only back to the mid-seventies, with the creation of the Sahelean AGRHYMET Programme (Centre de Formation et d'Applications en Agrométéorologie et Hydrologie Opérationnelle) in 1975. Before that period, rainy season quality monitoring was often limited to general statements such as "drought decreases the agricultural production". To have a quantitative idea of the effects of a possible drought, Governments had to wait for the results of the statistical surveys (if existing and reliable) or, in most cases, for the alarm signals from health clinics, from foreign agencies such as USAID or from the (international) press.

In Botswana, a study was carried out on the relations between rainy season quality and agricultural production, as part of the 1983-1987 project "Strengthening of National Meteorological Services" of the World Meteorological Organisation (W.M.O.), which is one of the United Nations Agencies. The purpose of the study was to provide the national Government with a reliable method for timely areawise livestock performance and crop state monitoring and for quantitative assessment of the national cattle herd size, cattle death ratio, total planted area and crop yield, which only uses weather data as input information. Some of the main results are summarised below and put within the more general framework of national (agricultural) planning and decision making.

\section{METHODOLOGY}

As appears from the introduction, the evaluation of the quality of a rainy season can not be reduced to a figure of total rainfall amount or its departure from the long term climatological mean: start, end and length of a rainy season and how the rainfall is distributed within the season are all factors to be taken into account. Moreover, the usefulness of a rainfall event will vary according to whether the soil has a low or high soil moisture storage capacity and depending upon the crop type and the development stage of the crop. High rainfall amounts are for example likely to be more useful during the flowering stage, when the crop is tall and vigorous and is about to start filling its grains; and maize will need (much) more regularly distributed water than the more drought resistant sorghum or millet. 
The models known to take into account all these factors are the water balance models. Their general principle is that the water requirements of a crop (or a grassland, or a forest, etc.) during a given development stage, are compared with the available rainfall and soil moisture reserve during that stage. For Botswana, three different models were developed and validated, one for livestock performance, one for planted area and one for crop development.

The first model assumes that optimal livestock performance goes along with minimum death ratios and that, throughout the year, an amount of rainfall equal to a fixed portion of potential evapotranspiration is needed to guarantee optimal growth of the range vegetation and optimum availability of drinking water (feed supply, recharge of boreholes, runoff of surface water to pools, etc.).

The second model assumes that the total area that can be planted under traditional rainfed farming, depends upon the total duration that the top layer of the soil is sufficiently wet to allow cattle, donkeys, oxen or tractors to pull the plough or the planter. In other words, the area that can be planted after a rainfall event would depend upon the evaporation rate of water from the top layer of a field.

The third model, finally, is based upon the fact that the water requirements of a crop increase gradually with its development, until the first stages of grain filling, after which these requirements decrease until complete maturity. Along with this development goes a root development model and possible different maximum available soil moisture reserves according to the soil and crop type.

The quality of a rainy season can than be expressed as the degree to which the water requirements for livestock, planted area and crop development were satisfied. The degree of this satisfaction, expressed as a percentage of the theoretical requirements is a Livestock Performance Index, a Planting Index or a Crop Index. As rainfall data become available during the progress of the rainy season, alarms can then possibly be issued when the degree of satisfaction of these requirements falls below a critical level and risks to result in a significant increase of cattle mortality, in an important decrease of the planted area, and/or in a significant yield reduction.

As agricultural production also highly depends upon the technological farming level, the presence of a possible time trend in the available series of data was also tested. This level can indeed change quickly with the introduction of new crop varieties, with the price of fertilizers, and with the adoptation by the farmer of new practices or equipment. These tests were carried out simultaneously with the analysis of the rainy season conditions, as it has been shown (4) that, depending upon weather conditions, the effects of technology on agricultural production can be significantly 
over or underestimated. (For example, a given fertilizer dose can result in a complete crop failure as a result of burning during a period of drought, but also in a bumper crop if the soil moisture conditions are adequate.)

\section{RESULTS}

\section{Livestock performance}

Both the interannual variability of the national cattle herd size (C) and of its mortality (D) are for $95 \%$ accounted for by the Livestock Performance Index (IL). It appears, however, that not only the quality of the current season (IL) is important, but also the conditions of the previous (IL-1) and of part of the third last rainy season (IL-2). For the national cattle mortality, expressed as the number of deaths as a percentage of total herd size (M), the mathematical expression of the influence of the rainy season conditions is as follows:

$$
\mathrm{M}=62.8-0.20 \mathrm{IL}-2-0.35 \mathrm{IL}-1-0.31 \mathrm{IL} 0
$$

This result confirms that livestock is less vulnerable to short term variations of the weather, probably because of its mobility, because of the fact that it feeds on natural vegetation which is, by definition, adapted to the local climate (interannual variability of the weather is part of the climate of a region) and because depletion of boreholes is rarely completed within one single season (5). Further analyses showed that this result can also be used for quantitative assessments of the national herd size and the national average cattle death ratio, with independent estimates obtained from the model having an error of less than $5 \%$ in all seasons. It appeared, however, that on an areal scale, the models' outputs can only find a reliable application in areawise monitoring of rainy season qualities for livestock performance.

Cattle is, after diamonds, Botswana's most important export product and the above results open important perspectives towards an improved planning and decision making in the fields of national scale livestock husbandry and market planning. As the variations of the national herd size, and thus of the exportable product, depend largely upon the nature of the last three rainy seasons, expected cattle numbers can be simulated according to different scenarios for the conditions of the coming one or two seasons. In the case of an expected important deterioration of the livestock performance, government decisions could then for example be taken to encourage cattle sales before the deterioration has advanced too far, when the condition of the livestock is still good enough to obtain acceptable prices. This would at the same 
TABLE 1

\begin{tabular}{|lcccc|}
\hline season & $\begin{array}{c}\text { planted area } \\
\text { (hectares) }\end{array}$ & $\begin{array}{c}\text { crop yield } \\
(\mathrm{kg} / \mathrm{ha})\end{array}$ & $\begin{array}{c}\text { production } \\
\text { (tons) }\end{array}$ & $\begin{array}{c}\text { rainfall } \\
(\mathrm{mm})\end{array}$ \\
\hline $1977 / 78$ & 260000 & 148 & 38500 & 609 \\
$1978 / 79$ & 171000 & 43 & 7400 & 328 \\
$1979 / 80$ & 270700 & 144 & 39000 & 506 \\
$1980 / 81$ & 270200 & 179 & 48400 & 603 \\
$1981 / 82$ & 182000 & 46 & 8500 & 308 \\
$1982 / 83$ & 222400 & 41 & 9000 & 366 \\
$1983 / 84$ & 187600 & 34 & 6500 & 378 \\
$1984 / 85$ & 203000 & 75 & 15500 & 291 \\
$1985 / 86$ & 230000 & 66 & 15000 & 343 \\
\hline
\end{tabular}


time result in a decrease of the herd size, hence in a decrease of the exploitation pressure of the natural range together with a decrease of the risk for overgrazing. Moreover, as the results also allow the areawise monitoring of the rainy season qualities, it becomes possible to identify problem areas during a given season and to make decisions accordingly. Examples of such decisions are: give marketing priorities to areas where the state of the range is expected to deteriorate, encourage transport of herds to more productive areas and, in extreme conditions, close acces to boreholes and areas with a high risk for overgrazing.

\section{Planted area and crop yield}

$95 \%$ of the variability of the nationwide planted area $(\mathrm{P})$ is accounted for by the total available moisture in the top layer of the soil in the first part of the planting season between October and early January (IP1), the available moisture in the top layer at the end of the planting period between early January and early February (IP 2 ) and by a positive time trend $(\mathrm{T})$. The mathematical expression of the relation is:

$$
P=-164.1+4.3 I P_{1}+1.4 I P_{2}+12.8 T
$$

(with: $P$, planted area in thousands of hectares and the season $1977 / 78$ being $\mathrm{T}=1$; IP is expressed as a percentage of the theoretical requirements)

Similarly, the variability of the rainfed traditional national crop yield (Y) is for $96 \%$ accounted for by the crop water requirement satisfaction index (IC) and a positive time trend $\mathrm{T}$; the mathematical expression is:

$$
Y=-169.1+4.6 I C+0.62 T^{2}
$$

(with: $\mathrm{Y}$, yield in $\mathrm{kg}$ per planted hectare)

These results are, from several points of view, very significant.

Over the period of analysis (1977/78-1985/86), both the planted area and crop yield show a significant negative time trend, as appears from Table 1 (source: 6,7 ).

The results show that, provided agricultural production, rainy season conditions and technological trend are analysed simultaneously, an apparently negative time trend can become a highly significant positive trend. The real value of the result then becomes that, despite drought conditions, the farmers of Botswana tend to increase 
the agricultural production by increasing both crop yield and planted area. Or in other words, entrepreneurship even during periods of drought.A similar case of a gross underestimation of the effects of a positive technological trend, resulting from not taking account of weather effects, has been reported for the maize and soya bean yields in the USA (4).

Another important information that can be derived from these results, at least from a socio-economic point of view, is that the drought strategy of Botswana's rainfed farmers is not haphasardeous, but well-considered. In fact, the positive time trend for crop yields, shows that farmers tend to rely on practices that decrease the dependency of their crop upon rainfall such as weeding, variety choice and crop failure risk spreading by spreading the plantings over a long period (11). This period is extended from end October to end January and increases the chances that at least some plantings will survive and yield some grain, even during a drought season. Certain other practices, such as the application of high fertiliser doses or high plant population densities or improved (and too often: imported) crop varieties, on the contrary, result in bumper yields, only provided the rainy season conditions are optimal. Under drought conditions, high population densities, inadequate fertilizer doses, and maladapted varieties can indeed result in burning of the crop and/or crop failure.

The contribution of the national Government to this positive time effect is probably not negligible. To decrease the dependency of the farmers on the unpredictable rainy season conditions, national programmes were conceived and implemented, such as the Arable Land Development Programme (ALDEP). This program aims, among others things, to encourage farmers to plant a crop by providing seeds, by partly funding mechanised draught power (tractors) and improved planters and by subsidizing the construction of fences around the fields (to reduce the risk of the crop being eaten by animals).

These agricultural programmes are being implemented together with health programmes, food distribution and labour-based drought relief programmes. Table 2 gives an idea of the increasing efforts of the Government in the fields of drought relief (source:8), together with the national average figures of the percentage number of children between 0 and 5 years old at nutritional risk (source:9).

A third, and probably the most important, aspect of the presented results is that it becomes possible to carry out adequate quantitative assessments of the national agricultural production and areawise qualitative monitoring of the rainy season conditions. An example of an areawise qualitative crop state monitoring is given in Figure 2. It is a map published in the Monthly Weather and Agrometeorological 


\begin{tabular}{|lcccc|}
\hline & $1982 / 83$ & $1983 / 84$ & $\begin{array}{c}1984 / 85 \\
(2)\end{array}$ & $\begin{array}{c}1985 / 86 \\
(3)\end{array}$ \\
\hline $\begin{array}{l}\text { Drought related } \\
\text { Government expenditure } \\
\text { (in billion Pula)(1) }\end{array}$ & 8.9 & 12.1 & 31.8 & 36.8 \\
$\begin{array}{l}\text { \% Children at } \\
\text { nutritional risk: }\end{array}$ & 29.7 & 29.7 & 17.0 & 15.3 \\
\hline
\end{tabular}

(1) : 1 pula equals approximately 0.6 US Dollar

(2): estimate

(3): as listed in the national budget

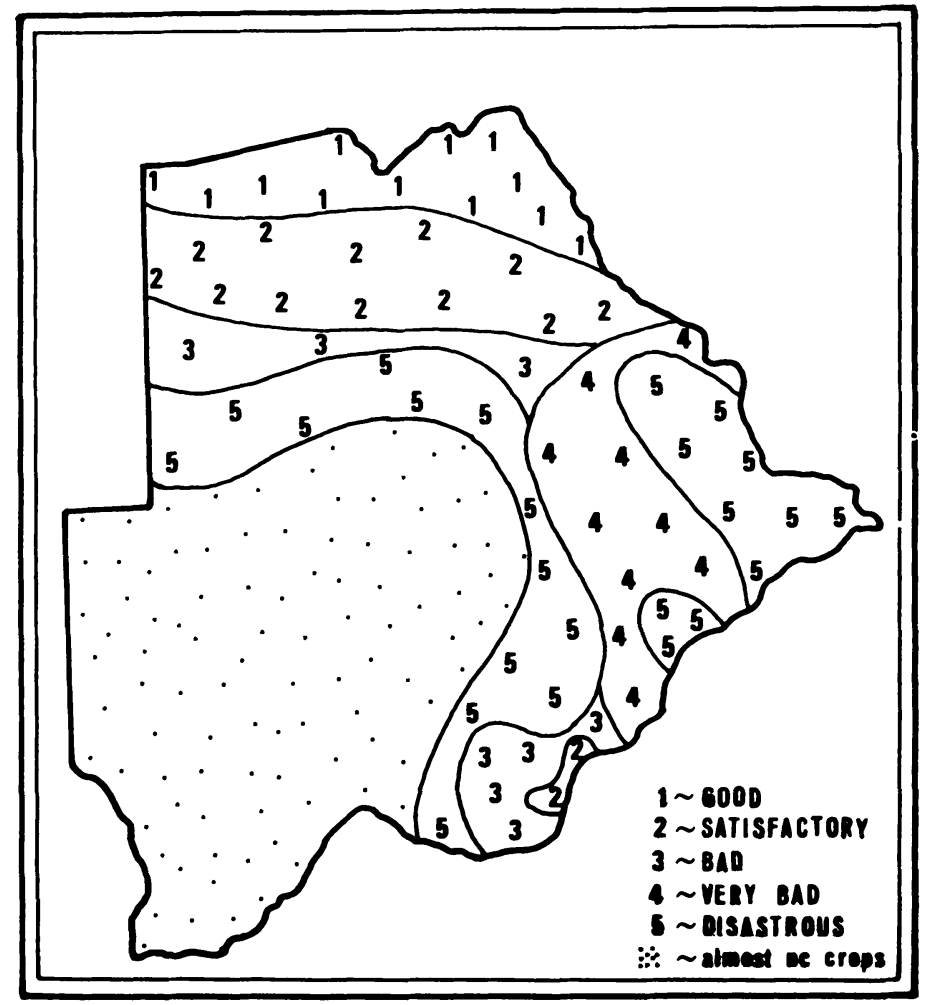

Figure 2: Evaluation of the quality of the rainy season for crop growth, February 1986. 


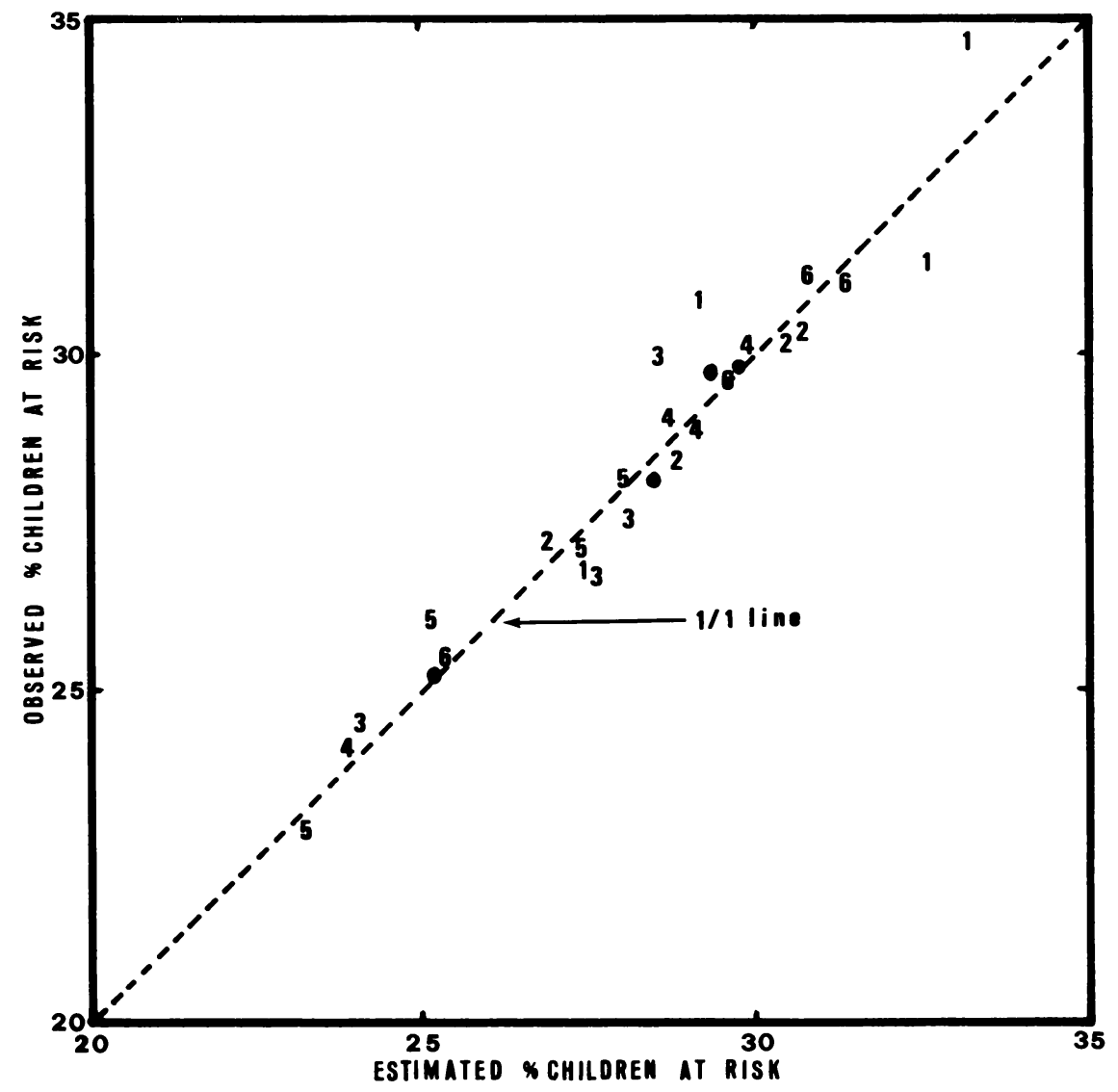

Figure 3: Comparison of 1979-1983 estimated with observed percentage numbers of children at ill nutritional risk, for 6 regions in Botswana.

1 = South-East; 2 = Gaborone ; 3 = Central ;

4 = Francistown; 5 = Ngamiland $; 6$ = Kgalagadi;

$o=$ national. (Source: 10) 
Bulletin of February 1986, tree months before the harvest and more than five months before the official, field observed statistics became available (7).

\section{The nutritional state of children}

Agricultural production and human food are closely linked, and a supplementary analysis was therefore carried out to relate the previously presented results to the statistics on the nutritional state of children between 0 and 5 years old (source: 9 ).

A homogeneous series of data was only available for the years 1979, 1980, 1982 and 1983, for 6 different areas covering the whole of Botswana. The years after 1983 were not considered, because as from 1984, the national drought relief programmes drastically decreased the numbers of children at nutritional risk. This is also illustrated in the previous table. The results are nevertheless promising, as appears from Figure 3. In this figure, the percentage of children at risk is defined as the number of children between 0 and 5 years old, with a weight below $80 \%$ of the WHO-reference weight for their age, and expressed as a percentage of the total number of children reporting at the Government Health Clinics of a region. The estimates were derived from a statistical relation between the percentage numbers of children at risk and the crop water requirements satisfaction index (10).

It thus appears that methods for crop (human food) state monitoring could be used in Botswana for the assessment of the risk of an increasing prevalence of malnutrition. It is, however, important to emphasize the fact that such methods should not be used for quantitative estimations or assessments of real numbers or percentages of children at nutritional risk, because they vary too much as a function of other factors such as food imports and distribution, health education, etc. (see table 2).

\section{CONCLUSIONS}

Agrometeorological modelling opens perspectives for adequate monitoring of rainy season conditions in Botswana (possibly in combination with quantitative estimates of national crop production or livestock performance). Operational and economically important applications can then be realized in the fields of areawise crop and human nutritional state monitoring, exact planning of cereal imports or cattle product exports, preservation of the natural range, reduction of overgrazing risk by livestock and fixing of priority areas, for example, for the construction of food stores. 


\section{acknowledgements}

This article reflects part of the activities carried out in the framework of the World Meteorological Organization / United Nations Development Programme / Botswana Government Project BOT/83/003. An extended version exists as a PhD-study (11), defended in 1989 at the Faculty of Agricultural Sciences of the State University of Gent and promoted by Prof.Dr.Ir.F.M.Pauwels, Dean of the Faculty.

\section{LITERATURE}

(1): Vossen, P., 1988. An analysis of agricultural livestock and traditional crop production statistics as a function of total annual and early, mid and late rainy season rainfall in Botswana. Agric.For.Meteorol., 42, 369-382.

(2): Bhalotra, Y.P.R., 1985. Rainfall maps of Botswana. Department of Meteorological Services, Republic of Botswana, Gaborone, 73 pp.

(3): Arntzen, J.W., Veenendaal, E.M., 1986. A profile of environment and development in Botswana. Institute of Environmental Studies, Free University of Amsterdam and National Institute of Development Research and Documentation, University of Botswana. Gaborone, 172 pp.

(4): Swanson, E.R., Nyankori, J.C., 1979. Influence of weather and technology on corn and soybean yield trends. Agric.Meteorol.,20, 327-342.

(5): Vossen, P., 1990. Simple water balance model for the assessment of livestock performance in Botswana. In print: Agric.For.Meteorol.

(6): Republic of Botswana, 1978-1987. Agricultural Statistics of the 1977/78 - 1985/86 rainy seasons. Published annually by the Ministry of Agriculture and the Ministry of Finance and Development Planning. Gaborone, variable number of pages.

(7): Republic of Botswana, 1976-1986. Monthly weather and agrometeorological bulletin. Published monthly by the Department of Meteorological Services. Gaborone, variable number of pages. 
(8): Hey, R.W., Burke, S., Dako, D.Y., 1986. A socio-economic assessment of drought relief in Botswana 1985. Report prepared by UNICEF / UNDP / WHO for the Interministerial Drought Committee, Republic of Botswana. Gaborone, $141 \mathrm{pp}+5$ annexes.

(9): Republic of Botswana, 1980-1987. Nutritional Surveillance: children under five at risk. Monthly published national and regional summary statistics. Ministry of Health. Gaborone, variable number of pages.

(10): Vossen, P., 1989. Possible use of a crop water balance model for the areawise assessment of the risks for malnutrition of children in Botswana as a result of drought. Submitted for publication to Agric.For.Meteorol.

(11): Vossen, P., 1989. Een agrometeorologische bijdrage tot het kwantitatief en kwalitatief beoordelen van het regenseizoen in Botswana. Doctoraatsthesis, Faculteit van de Landbouwwetenschappen, Rijksuniversiteit Gent. 